\title{
Facing the Beast Apart Together: Fear in Boys and Girls after Processing Information about Novel Animals Individually or in a Duo
}

\author{
Peter Muris • Sanne Rijkee
}

Published online: 12 October 2010

(C) The Author(s) 2010. This article is published with open access at Springerlink.com

\begin{abstract}
In this experimental study, we made an attempt to examine gender-related peer influences on childhood fear. Nine- to 12-year-old boys and girls were provided with ambiguous and positive information about novel animals and then asked to provide a subjective fear rating of the animals under two conditions: fear of one animal was assessed individually by the child on its own, whereas fear of the other animal was measured after a brief discussion on fear-related issues with a same-gender peer. Results indicated that children who completed the FBQ after a discussion with a same-gender peer displayed lower fear beliefs scores than children who completed the questionnaire fully on their own. This fear-suppression effect was mainly evident in boys after hearing ambiguous information about the novel animals. The implications of these findings are briefly discussed.
\end{abstract}

Keywords Fear · Children · Peer influences .

Information transmission $\cdot$ Gender role

\section{Introduction}

Fears are quite common among children. For example, Ollendick et al. (1989) found an average of 14 fears reported by American and Australian youths aged 7 to 17 years, and there are good reasons to believe that this

P. Muris $(\varangle) \cdot$ S. Rijkee

Institute of Psychology, Erasmus University Rotterdam,

Burgemeester Oudlaan 50, Suite T13-37, P.O. Box 1738,

Rotterdam, The Netherlands

e-mail: muris@fsw.eur.nl number is quite similar across children in various countries (see Gullone 2000). Most of these fears are concerned with dangerous situations and physical harm (e.g., Craske 1997), and seem to be instigated by information provided by caregivers who try to warn their offspring for the potential danger of unfamiliar stimuli and situations (Rachman 1977; see Muris et al. 2010).

It is a well-known fact that girls generally report higher levels of fear as compared to boys (e.g., Ollendick et al. 2002). One explanation for this difference between boys and girls is concerned with children's gender role orientation (Ollendick et al. 1995). Briefly, this explanation implies that girls and boys are socialized to develop gender-linked behaviors, traits, and skills. According to theories on the development of gender roles (e.g., Bem 1981), the expression of fear is in agreement with the feminine gender role and as such more tolerated when displayed by girls. Conversely, fear is inconsistent with the masculine gender role as boys are expected to behave brave and courageously. There is indeed some evidence showing that gender role orientation is predictive of the intensity of children's fear, with femininity being positively and masculinity being negatively related to fear levels (Ginsburg and Silverman 2000; Muris et al. 2005; Palapattu et al. 2006).

Research has indicated that parental rearing practices are involved in the development of children's fear (e.g., Bögels and Brechman-Toussaint 2006). Further, it is increasingly acknowledged that mothers and fathers seem to play a different role in this process. Mothers generally display a more protective attitude within the context of fear, while fathers usually exhibit more risk-taking and courageous behaviors (Bögels and Phares 2008), which is in agreement with the earlier described gender role account. Meanwhile, it is also possible that children's 
expression of fear is influenced by their peers. So far, surprisingly little is known about the extent to which childhood fears are affected by the interaction with young people of their own age. Especially during middle childhood when boys and girls show a strong preference for same-sex peers (Cole and Cole 1996), it may well be that gender role-related attitudes and behaviors have an impact on the expression of children's fears. More precisely, it is well-conceivable that boys mutually decrease their fears as they try to comply with the masculine gender role, whereas girls reciprocally intensify their fears because they attempt to accommodate to the feminine gender role.

The present study represents a first attempt to investigate this issue empirically. Adopting the experimental method as developed by Field et al. (2001), 9- to 12-year-old boys and girls were provided with ambiguous and positive information about novel animals (i.e., Australian marsupials) and then asked to provide a subjective fear rating of the animals. For each child, the procedure was conducted under two conditions: fear of one animal was assessed individually by the child on its own, whereas fear of the other animal was measured after a discussion on fearrelated issues with a same-gender peer. In this way, the following hypotheses were tested: (1) children will display higher fear levels for animals for which ambiguous information has been provided than for animals for which positive information has been given, (2) girls will report higher fear levels in relation to the unknown animals than boys, and (3) girls who evaluate the fear level of the animals after a discussion with a same-gender peer will display higher levels of fear than boys who evaluate the fear level of the animals after having talked about this with a same-gender peer. It can be expected that the latter hypotheses are best testable under the condition that boys and girls are provided with ambiguous information, as the positive information can be expected to yield equally low fear levels in all children. In order to control for the effect of individual differences in general fearfulness, children also completed a standardized fear survey.

\section{Method}

\section{Participants}

Eighty-children ( 44 boys and 36 girls) were recruited from a regular school in Rotterdam, The Netherlands, by sending their parents an information letter about the study along with a consent form. Initially, parents of 100 children were contacted, which means that the response rate in this study was $80 \%$. Mean age of the participating children was 10.0 years $(S D=1.0$; range $9-12$ years $)$.

\section{Pictures and Stories}

Pictures of two Australian marsupials (the Cuscus and the Quokka) were downloaded from the internet and printed on A4-sheets. These animals are not known to Dutch youths, and because of this lack of prior experience it can be assumed that children have no prior ideas about their life style. Information about the animals that was given to the children consisted of 10 sentences, which were provided in two versions: ambiguous and positive (see Appendix A). Sentences were formulated in such way that they unambiguously reflected the intended information category, and were matched for content so that they referred to comparable behaviors and characteristics of the animals. Note further that this information has been successfully employed in previous research in order to manipulate children's fear about novel animals (e.g., Muris et al. 2009b).

A shortened version of the Fear Survey Schedule for Children-Revised (FSSC-R; Ollendick 1983) was employed to assess children's general levels of fearfulness. This questionnaire consists of 25 items that measure the intensity of children's fears (e.g., "Being hit by a car or truck", "Going to bed in the dark", and "Making mistakes"). Each item is scored on a three-point scale with $1=$ no fear, $2=$ some fear, and $3=$ a lot of fear. A FSSC-R total score (Cronbach's alphas $=.81$ ) was computed by summing across all items (range 25-75). The short version of the FSSC-R correlates .97 with the full-length scale, which has been shown to be highly reliable in terms of internal consistency and test-retest stability. Further, support has been found for the validity of the FSSC-R. Specifically, scores on this scale correlate substantially with other childhood anxiety measures (Muris et al. 2002) and are useful in differentiating specific types of phobias (Weems et al. 1999).

The Fear Beliefs Questionnaire (FBQ; Field et al. 2001) that was used in the present study consisted of 10 items: (1) "If you had a Cuscus/Quokka as pet, would you be afraid when you had to clean its cage?"; (2) "Would you find it scary to feed a Cuscus/Quokka?"; (3) "Would you find it scary to touch a Cuscus/Quokka?"; (4) Would you quickly run away if you saw a Cuscus/Quokka?"; (5) "Do you think that a Cuscus/Quokka will bite you?"; (6) Would you feel scared if you encounter a Cuscus/Quokka?"; (7) Do you think that the Cuscus/Quokka will hurt you?"; (8) Would you go quickly inside if you would see a Cuscus/ Quokka near your house?"; (9) "Do you believe that the Cuscus/Quokka can make you ill?"; and (10) "Would you be nervous if you had to enter a room with a Cuscus/ Quokka?". Items have to be rated on a 5-point Likert scale with $1=$ No, not at all, $2=$ No, not really, $3=Y e s$, maybe, $4=$ Yes, probably, and $5=$ Yes, definitely. A total 
fear belief score can be computed by summing the ratings on all items (range 10-50). Cronbach's alphas of the FBQ in the present study varied between .79 and .87 , which is well in line with previous studies which demonstrated that this scale provides a reliable index of fear beliefs, which is highly sensitive to document the effects of verbal information (see for a review Muris and Field 2010).

\section{Procedure}

Figure 1 provides a schematic overview of the procedure of the present study. After obtaining written informed consent from children's parents, boys and girls were tested twice by a female experimenter in a separate room at school. During phase 1, each child was tested individually: he/she first received either ambiguous or positive information about the Cuscus or the Quokka (which were presented in a counterbalanced fashion across the two phases of the experiment in order to minimize possible animalrelated effects) and then completed the FBQ. During phase 2, which took place on the next day, the child was tested together with a quasi-randomly selected same-sex peer from his class (the teacher made sure that close friends were not tested jointly). Children were provided with either ambiguous or positive information about the Cuscus or the Quokka (dependent on the information and the animal that they confronted with during phase 1), after which they were explicitly asked to confer with each other for $5 \mathrm{~m}$ about possible answers to each of the questions raised in the FBQ, before filling out the questionnaire on their own. During the completion of the scale, children were clearly separated by the experimenter, and no longer allowed to communicate. Following this, children were debriefed and provided with some real information about the lifestyle and behaviors of Cuscusses and Quokkas. Finally, children were thanked for their participation by giving them a small present.

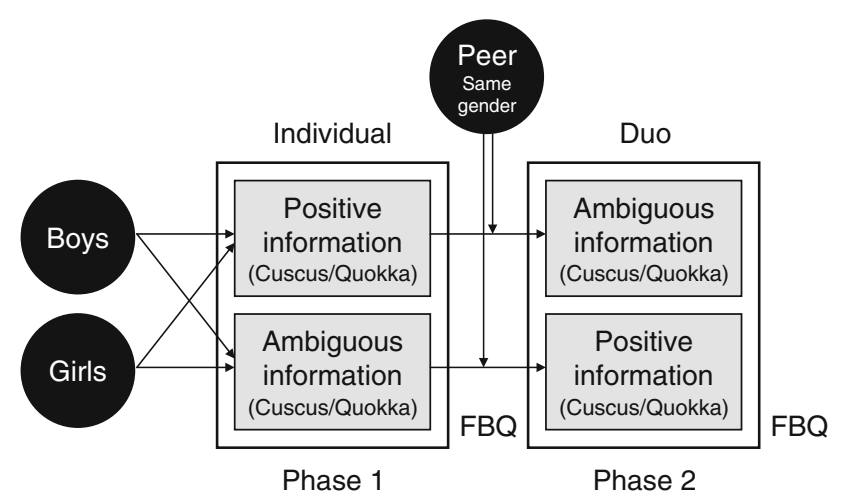

Fig. 1 Overview of the design of the present experiment. Note. FBQ fear beliefs questionnaire

\section{Results}

A preliminary analysis indicated that children in general provided highly comparable fear beliefs ratings for the Cuscus and the Quokka (which is in keeping with previous research, e.g., Field 2006; Muris et al. 2009a), and this appeared true for the individual as well as for the duo condition [both $t(78) \mathrm{s}<1$ ]. Therefore, and also in view of the fact that animals were presented to children in a counterbalanced fashion, it seemed permissible to combine the data and not to include animal as a factor in the statistical analysis. Table 1 displays mean fear beliefs scores of children in various experimental conditions. A series of mixed design analyses of variance with children's general level fearfulness (FSSC-R) ${ }^{1}$ as covariate (ANCOVAs) were conducted to test the effects of gender (boys vs. girls), information type (ambiguous vs. positive), and experimental condition (individual vs. duo).

\section{Effects of Information: Positive Versus Ambiguous}

A 2 (gender) $\times 2$ (information type) ANCOVA performed on the FBQ data as obtained during the individual phase (i.e., phase 1) of the experiment yielded significant main effects of information type $[F(1,75)=8.72, p<.01$, partial $\left.\mu^{2}=.10\right]$ and the covariate FSSC-R $[F(1,75)=14.98$, $p<.001$, partial $\left.\mu^{2}=.17\right]$. No significant main effect of gender or an interaction effect of gender and information type were found [both $F(1,75)$ s $<1$ ]. These findings indicate that during the individual phase of the experiment, boys and girls were similarly affected by the type of information they received from the experimenter. That is, in both genders the ambiguous information produced higher levels of fear beliefs in relation to the novel animals than the positive information $(p s<.05)$. Further, fear beliefs were somewhat inflated in children who displayed higher levels of general fearfulness, which was supported by a positive correlation between the FSSC-R and the FBQ within each information type condition (ambiguous: $r=.39$, positive: $r=.48$, both $p$ s $<.05$ ).

A similar 2 (gender) $\times 2$ (information type: ambiguous vs. positive) ANCOVA was carried out on the data collected during the duo phase (i.e., phase 2) of the experiment. Results indicated that there was a significant main effect of information type $[F(1,75)=42.21, p<.001$, partial $\mu^{2}=.39$ ]: again ambiguous information yielded higher levels of fear beliefs than positive information. In addition, a main effect of gender was found $[F(1,75)=$ 6.08, $p<.05$, partial $\left.\mu^{2}=.08\right]$ : girls generally displayed

\footnotetext{
${ }^{1}$ Girls scored significantly higher on the FSSC-R than boys, means being 39.28, $S D=6.56$ and $34.36, S D=4.83$, respectively $\left[F(1,78)=14.82, p<.001\right.$, partial $\left.\mu^{2}=.16\right]$.
} 
Table 1 Mean fear beliefs (FBQ) scores (standard errors) of boys and girls in various experimental conditions

\begin{tabular}{llllll}
\hline & \multicolumn{2}{l}{ Individual } & & \multicolumn{2}{c}{ Duo } \\
\cline { 2 - 3 } \cline { 5 - 6 } & Boys & Girls & Boys & Girls \\
\hline Ambiguous information & $20.04(.93)_{\mathrm{a}}$ & $19.52(1.08)_{\mathrm{a}}$ & & $16.24(.69)_{\mathrm{b}}$ & $18.96(.73)_{\mathrm{a}}$ \\
Positive information & $17.21(1.01)_{\mathrm{c}}$ & $16.47(1.06)_{\mathrm{c}}$ & & $12.41(.63)_{\mathrm{d}}$ & $13.34(.74)_{\mathrm{d}}$ \\
\hline
\end{tabular}

$F B Q$ fear beliefs questionnaire. Scores were corrected for children's general fearfulness scores as measured by the shortened Fear Survey Schedule for Children-Revised (FSSC-R). Means within the same row/column that do not share similar subscripts differ at $p<.05$

somewhat higher FBQ scores as compared to boys, although it should be noted that this was only significant in case ambiguous information was provided $(p<.05$; see Table 1). No further effects reached statistical significance $[F(1,75) \mathrm{s} \leq 1.72, p \mathrm{~s} \geq .19]$.

\section{Effects of Experimental Condition: Individual Versus Duo}

To study the effects of the experimental condition in more detail, a set of additional statistical analyses was conducted. A 2 (gender) $\times 2$ (condition: individual vs. duo) ANCOVA (with the last factor being a repeated measure) performed on the fear beliefs scores of the animal for which children had received ambiguous information revealed significant main effects of condition $[F(1,75)=$ $4.69, p<.05$, partial $\mu^{2}=.06$ ] and FSSC-R general fearfulness $\left[F(1,75)=10.26, p<.01\right.$, partial $\left.\mu^{2}=.12\right]$. There was neither a significant main effect of gender nor an interaction effect of gender and condition [both $F(1,75)$ s $<$ 1], although it should be mentioned that post-hoc-comparisons indicated that boys who completed the FBQ in a duo after hearing ambiguous information about novel animals had significantly lower scores than all other groups $(p \mathrm{~s}<.05$; Table 1$)$.

A 2 (gender) $\times 2$ (condition: individual vs. duo) ANCOVA performed on the fear beliefs scores of the animal for which children had received positive information again yielded significant main effects of condition $\left[F(1,75)=35.77, p<.001\right.$, partial $\left.\mu^{2}=.32\right]$ and FSSC-R general fearfulness $[F(1,75)=3.98, \quad p=.05$, partial $\left.\mu^{2}=.05\right]$. Post-hoc comparisons showed that boys and girls in response to animals for which they had received positive information both reported lower levels of fear beliefs after they had discussed the items of the FBQ together with a same-gender peer than when they filled out the scale on their own $(p s<.05)$.

\section{Discussion}

The present study employed Field et al.'s (2001) information transmission paradigm in order to investigate gender-related fear-promoting effects of peers in middle childhood. Boys and girls were provided with ambiguous and positive information about two novel animals for which they were asked to complete a self-report fear scale, either fully on their own or after a brief discussion with a same-gender peer. The results can be summarized as follows. To begin with, ambiguous information yielded higher levels of fear beliefs in relation to novel animals than positive information, which is in keeping with previous research comparing the effects of these types of information on children's fear (e.g., Muris et al. 2009b, 2010). In essence, the ambiguous information as provided in the current study is not threatening on its own, but it is a welldocumented fact that children may show a tendency to interpret ambiguity in a threatening way. This is particularly true for anxious and fearful children, who consistently display this inclination which that has been labeled as 'interpretation bias' (Muris and Field 2008).

Further, as for gender differences in fear, minimal support was found for the hypothesis that girls would report higher fear levels in relation to the unknown animals than boys. That is, only after receiving ambiguous information about the novel animals, girls in general displayed somewhat higher FBQ scores, although it should be mentioned that this effect was mainly carried by the data collected in the duo condition. Otherwise, no significant differences in the fear evaluation of the animals between boys and girls emerged, which is not what one would expect on the basis of the existing literature (see for a review Gullone 2000). Meanwhile, the expected gender difference in fear was found on the FSSC-R: that is, girls clearly displayed higher scores on this measure of general fearfulness than boys. Note also that we controlled for this variable in all statistical analyses, and that this procedure might have prevented the finding of more clear-cut gender differences in fear beliefs about the novel animals.

Finally, the most interesting finding of the present study was that children who completed the FBQ after a discussion with a same-gender peer displayed lower fear beliefs scores than children who completed the questionnaire fully on their own. Post-hoc comparisons indicated that this was especially true when children were confronted with positive information about the novel animals. When exposed to 
ambiguous information, this fear-suppression effect of duos was clearly less prominent. Only boys who had discussed the FBQ items together exhibited lower fear beliefs scores as compared to when they filled in the scale individually, while girls provided similarly high fear beliefs ratings in the duo and individual condition. This result provides tentative support for a gender-role-related fearsuppression effect, which would be operating in boys. That is, when boys jointly evaluate a potential threat, they might show a stronger tendency to downscale the dangerousness of that stimulus or situation, which is of course in keeping with their dominant gender role prescribing not to show negative emotions such as fear (Bem 1981). Girls do not show this effect and appear to be less sensitive for the presence of a same-gender peer when evaluating ambiguous stimuli and situations.

It should be borne in mind that this research suffers from various limitations. First of all, one could argue that the general fear-suppression effect as observed in this study was merely due to the fact that the duo condition always followed the individual condition, and that the lower fear beliefs rating in the former primarily reflected some kind of test-retest habituation effect. Note, however, that this explanation is not very plausible, as previous studies which also employed within-subjects comparisons of various novel animals did not reveal such an effect of a repeated administration of the FBQ (e.g., Field 2006; Muris et al. 2009a). Second, the study mainly relied on children's selfreport of fear beliefs, and so it will be important for future studies to also include other indices of fear such as a behavioral test or a physiological assessment. Third, children in the duo condition were classmates, which means that they were to some extent acquainted to one another. Also, in some duos children might have known each other better than in others. To eliminate such unwanted effects, it would be better to make pairs of children who are complete strangers to each other. Fourth, the study did not include a control group of mixed-gender pairs. It would be interesting to see what kind of influence boys have on girls' fear beliefs ratings and vice versa. Fifth and finally, we did not audiotape the conversations of the duos. This would have made it possible to make an analysis of differences in the content of the communication between boys and girls, and might provide us a better clue about where the fear-suppression effect of boys precisely originates from.

As for the practical implications of this work, there is increasing empirical evidence showing that positive information is a viable strategy to reduce children's fear (Kelly et al. 2010; Muris et al. submitted). The present findings are thought-provocative in that they suggest that, at least in middle childhood, children could be asked to process positive information about novel, potentially fear-eliciting stimuli with their peers, as this may result in lower levels of fear. Surprisingly few studies have investigated peer influences on childhood fear (for an exception, see Ollendick et al. 1995), and this topic indeed seems to be a worthwhile scientific endeavor.

Open Access This article is distributed under the terms of the Creative Commons Attribution Noncommercial License which permits any noncommercial use, distribution, and reproduction in any medium, provided the original author(s) and source are credited.

\section{Appendix A}

Information that employed in the present study to manipulate children's fear beliefs about the novel animals.

\section{Ambiguous}

The Cuscus/Quokka has white teeth.

The Cuscus/Quokka eats all sorts of things.

The Cuscus/Quokka can jump.

The Cuscus/Quokka has a unique smell.

The Cuscus/Quokka is noticeable.

The Cuscus/Quokka lives like some other animals.

The Cuscus/Quokka makes noises.

The Cuscus/Quokka likes to drink all sorts of things.

The Cuscus/Quokka has claws and scratches trees.

You never know what the Cuscus/Quokka will do.

\section{Positive}

The Cuscus/Quokka has nice tiny teeth.

The Cuscus/Quokka eats tasty strawberries.

The Cuscus/Quokka hops around.

The Cuscus/Quokka smells nice.

You can have fun with the Cuscus/Quokka.

The Cuscus/Quokka likes to play with other animals.

The Cuscus/Quokka purrs softly.

The Cuscus/Quokka likes to drink lemonade.

The Cuscus/Quokka has no claws and soft pads on its feet.

The Cuscus/Quokka is always good-natured.

\section{References}

Bem, S. L. (1981). Gender schema theory: A cognitive account of sex typing. Psychological Review, 88, 354-364.

Bögels, S. M., \& Brechman-Toussaint, M. L. (2006). Family issues in child anxiety: Attachment, family functioning, parental rearing, and beliefs. Clinical Psychology Review, 26, 834-856.

Bögels, S. M., \& Phares, V. (2008). Fathers' role in the etiology, prevention and treatment of child anxiety: A review and new model. Clinical Psychology Review, 28, 539-558.

Cole, M., \& Cole, S. R. (1996). The development of children. New York: Freeman. 
Craske, M. G. (1997). Fear and anxiety in children and adolecents. Bulletin of the Menninger Clinic, 61(Suppl.A), A4-A36.

Field, A. P. (2006). Watch out for the beast: Fear information and attentional bias in children. Journal of Clinical Child and Adolescent Psychology, 35, 431-439.

Field, A. P., Argyris, N. G., \& Knowles, K. A. (2001). Who's afraid of the big bad wolf: A prospective paradigm to test Rachman's indirect pathways in children. Behaviour Research and Therapy, $39,1259-1276$.

Ginsburg, G. S., \& Silverman, W. K. (2000). Gender role orientation and fearfulness in children with anxiety disorders. Journal of Anxiety Disorders, 14, 57-67.

Gullone, E. (2000). The development of normal fear: A century of research. Clinical Psychology Review, 20, 429-451.

Kelly, V. L., Barker, H., Field, A. P., Wilson, C., \& Reynolds, S. (2010). Can Rachman's indirect pathways be used to un-learn fear? A prospective paradigm to test whether children's fears can be reduced using positive information and modelling a nonanxious response. Behaviour Research and Therapy, 48, 164-170.

Muris, P., \& Field, A. (2008). Distorted cognition and pathological anxiety in children and adolescents. Cognition and Emotion, 22, 395-421.

Muris, P., \& Field, A. P. (2010). The role of verbal threat information in the development of childhood fear. "Beware the Jabberwock!". Clinical Child and Family Psychology Review, 13, $129-150$.

Muris, P., Huijding, J., Mayer, B., Leemreis, W., Passchier, S., \& Bouwmeester, S. (2009a). The effects of verbal disgust- and threat-related information about novel animals on disgust and fear beliefs and avoidance in children. Journal of Clinical Child and Adolescent Psychology, 38, 551-558.

Muris, P., Huijding, J., Mayer, B., Van As, W., \& Van Alem, S. (submitted). Reduction of verbally learned fear in children: A comparison between positive information, emotive imagery, and a no-intervention control condition.

Muris, P., Meesters, C., \& Knoops, M. (2005). The relation between gender role orientation and fear and anxiety in non-clinic referred children. Journal of Clinical Child and Adolescent Psychology, 34, 326-332.
Muris, P., Merckelbach, H., Ollendick, T. H., King, N. J., \& Bogie, N. (2002). Three traditional and three new childhood anxiety questionnaires: Their reliability and validity in a normal adolescent sample. Behaviour Research and Therapy, 40, 753-772.

Muris, P., Rassin, E., Mayer, B., Smeets, G., Huijding, J., Remmerswaal, D., et al. (2009b). Effects of verbal information on fear-related reasoning biases in children. Behaviour Research and Therapy, 47, 206-214.

Muris, P., Van Zwol, L., Huijding, J., \& Mayer, B. (2010). Mom told me scary things about this animal! Parents installing fear beliefs in their children via the verbal information pathway. Behaviour Research and Therapy, 48, 341-346.

Ollendick, T. H. (1983). Reliability and validity of the revised fear survey schedule for children (FSSC-R). Behaviour Research and Therapy, 21, 685-692.

Ollendick, T. H., King, N. J., \& Frary, R. B. (1989). Fears in children and adolescents: Reliability and generalizability across gender, age, and nationality. Behaviour Research and Therapy, 27, 19-26.

Ollendick, T. H., Yang, B., Dong, Q., Xia, Y., \& Lin, L. (1995). Perceptions of fear in other children and adolescents: The role of gender and friendship status. Journal of Abnormal Child Psychology, 23, 439-452.

Ollendick, T. H., King, N. J., \& Muris, P. (2002). Fears and phobias in children: Phenomenology, epidemiology, and aetiology. Child and Adolescent Mental Health, 7, 98-106.

Palapattu, A. G., Newman Kingery, J., \& Ginsburg, G. S. (2006). Gender role orientation and anxiety symptoms among African American adolescents. Journal of Abnormal Child Psychology, $34,441-449$.

Rachman, S. (1977). The conditioning theory of fear acquisition: A critical examination. Behaviour Research and Therapy, 15, 375-387.

Weems, C. F., Silverman, W. K., Saavedra, L. M., Pina, A. A., \& Lumpkin, P. W. (1999). The discrimination of children's phobias using the revised fear Survey schedule for Children. Journal of Child Psychology and Psychiatry, 40, 941-952. 